\title{
Escribir la violencia hacia las mujeres. Feminismo, afectos y hospitalidad
}

\author{
Mariela Peller ${ }^{1}$ (i) 0000-0001-5393-0306 \\ Alejandra Oberti2 (iD) 0000-0001-8813-2523 \\ 'Universidad de Buenos Aires, Ciudad de Buenos Aires, Argentina. C1420 - \\ iiegeuba@gmail.com \\ 2Universidad de Buenos Aires, Ciudad de Buenos Aires, Argentina. C1425 - \\ iealc@sociales.uba.ar
}

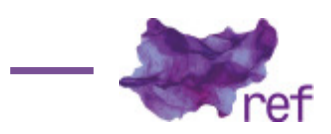
Resumen: El artículo examina tres obras literarias contemporáneas argentinas que intervienen en las
discusiones sobre el estatuto social de la violencia sexista y sus políticas de visibilización. Desde una
perspectiva enmarcada en el movimiento feminista y sus redes afectivas, se analizan Beya (le viste la
cara a Dios), de Gabriela Cabezón Cámara e Iñaki Echeverría (2013), Chicas muertas, de Selva Almada
(2014) y Por qué volvías cada verano, de Belén López Peiró (2018). Son obras que abordan temas clásicos
del feminismo -prostitución, femicidio y violación-, produciendo torsiones en los lugares sociales, en
las posibilidades de toma de la palabra y en los archivos. No solo marcan la trama social que produce
las violencias -y sus responsables- sino que también despliegan políticas de resistencia que permiten
a las mujeres imaginarse más allá de victimizaciones en un colectivo amoroso.
Palabras-clave: literatura argentina contemporánea; feminismo; afectos; violencia sexista; mujeres.

Writing Violence Against Women. Feminism, Affect and Hospitality

Abstract: This article examines three contemporary Argentine literary works involved in discussions about the social status of sexist violence and its visibility politics. From a perspective framed in the feminist movement and its affective networks, our analysis focus on Beya (le viste la cara a Dios), by Gabriela Cabezón Cámara e Iñaki Echeverría (2013), Chicas muertas, by Selva Almada (2014) and Por qué volvías cada verano, by Belén López Peiró (2018). These are works that address classic feminist issues prostitution, femicide and rape-producing torsions in social places, in the possibilities of speaking, and in the archives. They not only mark the social scheme that produces violence-and those responsible for it- but also display resistance politicies that allow women to imagine themselves beyond victimization in a loving collective.

Keywords: Contemporary Argentine Literature; Feminism; Affect; Sexist Violence; Women.

Escrever a violência contra as mulheres. O feminismo, afetos e hospitalidade

Resumo: O artigo examina três obras literárias argentinas contemporâneas envolvidas em discussões sobre o status social da violência sexista e suas políticas de visibilidade. Com uma perspectiva enquadrada no movimento feminista e em suas redes afetivas, são analisados Beya (le viste la cara a Dios), de Gabriela Cabezón Cámara e Iñaki Echeverría (2013), Chicas Muertas, de Selva Almada (2014) e Por qué volvías cada verano, de Belén López Peiró (2018). São trabalhos que abordam temas clássicos do feminismo - prostituição, femicídio e estupro -, produzindo torções em espaços sociais, nas possibilidades de falar e nos arquivos. Eles não apenas marcam a trama social que produz a violência - e os responsáveis por ela -, mas também exibem políticas de resistência que permitem às mulheres se imaginar além da vitimização em um coletivo amoroso.

Palavras clave: literatura argentina contemporânea; feminismo, afetos, violência sexista; mulheres. 


\section{Introducción}

¿Cómo representar la violencia hacia las mujeres? ¿Quién debe y quién puede asumir esa tarea? ¿Mediante qué estrategias formales? En este artículo queremos aproximarnos a los modos en que algunas obras literarias argentinas contemporáneas escritas por mujeres intervienen tanto en las discusiones sobre el estatuto social de la violencia sexista como en los alcances de la (re) presentación y de las políticas de visibilización de esas formas de violencia. La perspectiva de análisis propuesta no está enmarcada en la crítica literaria, sino en la política de lectura del movimiento feminista, sus redes de solidaridad y afectos, el uso de la literatura y las imágenes como lugares de expresión de lo afectado por las violencias y a la vez de producción de políticas de resistencia. El movimiento feminista ha denunciado al patriarcado como un sistema de opresión que tiene diversos puntos de anclaje, que se asienta en la cultura y en la ideología, y que no ha permanecido idéntico a sí mismo a lo largo de los siglos, sino que ha sido capaz de transformarse y adaptarse a diferentes contextos. Se trata de una forma de opresión que teje lazos, se nutre de y nutre a otras formas de explotación y desigualdad. El feminismo entendido como la práctica histórica de los movimientos de mujeres ha producido una confrontación y reconceptualización de la experiencia sexual de las mujeres que no entiende la violencia como una ruptura del orden social, sino como resultado de una lucha de poder para el sostén de una cierta clase de orden social (Teresa DE LAURETIS, 1994). En el marco de las relaciones patriarcales, la violencia sexista se ha extendido a lo largo de la historia, pero solamente en las últimas décadas y por presión del movimiento feminista ha sido reconocida como una de las violaciones a los derechos humanos más graves por su frecuencia y extensión. Como ha quedado establecido de manera persistente en las últimas décadas, la violencia contra las mujeres es un problema de derechos humanos que afecta la integridad personal, la salud, deteriora la calidad de vidas, atenta contra los derechos civiles, económicos, sociales y culturales. A la vez, se articula con otras formas desigualdad y violencia como las raciales, étnicas y económicas.

Como señala Alejandra Laera (2010), David Viñas postula en su texto Literatura argentina y realidad política, de 1971, que la literatura argentina emerge alrededor de la violación sexual como metáfora: desde El matadero, de Esteban Echeverría, el libro que funda la literatura nacional, pasando por Mármol, Sarmiento y otros. En un sentido similar, Cristina Iglesia señala que en "EI Matadero, la violencia y la vejación son absolutamente gratuitas desde la lógica de la guerra. La única justificación posible es la necesidad de que un bando no ocupe el espacio del otro" (IGLESIA, 2004, p. 34). La violación, según la influyente sentencia de Viñas, es una metáfora de la construcción de la nación y del lugar de los sujetos en ella, del pueblo y de la violencia de las relaciones sociales, en definitiva, una metáfora del funcionamiento de la política.

En "La violencia de la retórica. Consideraciones sobre representación y género", Teresa de Lauretis (1994) contrapone los usos de la mujer como símbolo de la verdad (Nietzsche) y el devenir mujer de la filosofía (Derrida) a la construcción social de mujer y varón que proviene del movimiento feminista. La diferencia entre los dos conceptos de mujer consiste en que mientras los filósofos hablan desde esa posición porque la reconocen como vacante (por disponible y por vacía), para el feminismo se trata de la producción semiótica de la subjetividad sexuada. En analogía con esta perspectiva, se puede señalar que la representación discursiva de las relaciones sociales o la fundación de la nación como violencia sexual desconoce la experiencia de la violencia que sufren las mujeres, es decir, las prácticas sociales de la violencia. La violencia sexual, la violación -más allá de que sea ejecutada sobre un cuerpo masculino- como metáfora de la política, solo puede formar parte de un corpus literario extenso a costa del desconocimiento de la violencia (sexual) real y de los sujetos que la padecen mayoritariamente, es decir, de las mujeres.

Del planteo de Teresa de Lauretis surgen tres elementos que resultan útiles para el análisis que proponemos en estas páginas. En primer lugar, la relación compleja entre las representaciones discursivas (en este caso el uso simbólico de mujer o metafórico de violación) y las prácticas sociales (la violación). En segundo lugar, la consideración de la violación como práctica sexual. ${ }^{1}$

\footnotetext{
' En este punto Teresa de Lauretis menciona la discusión sobre el lugar de la violación en el código penal francés en la cual intervinieron Michel Foucault y algunos grupos feministas. En esa discusión, que se produjo en ocasión de las propuestas de reforma de dicho código a fines de los años 70 , Foucault insistió en considerar a la violación fuera del dominio de lo sexual, tratándola solamente como violencia. Las feministas, por otra parte, señalaron que esa consideración permitiría oponerse a la violencia sexual, sin cuestionar hasta qué punto la institución de la heterosexualidad ha definido la fuerza como una expresión normal de las relaciones (hetero)sexuales (DE LAURETIS, 1994). La propuesta de Foucault es parte del esfuerzo por liberar a los comportamientos sexuales de la influencia de la ley y de ese modo eximir a la esfera de lo sexual de la intervención estatal, es decir, como una forma de resistencia local. La respuesta de algunas feministas fue que la violación es una práctica sexual y es un problema que se basa en la diferencia social entre los sexos. Teresa de Lauretis considera que por más esclarecedora que sea la obra de Foucault para la comprensión de la mecánica del poder en las relaciones sociales, su valor crítico está cercenado por su indiferencia por lo que podríamos llamar, de acuerdo con él mismo, "tecnología del género". Es decir, por las técnicas y estrategias discursivas mediante las cuales el género es construido y el lugar de la violencia en esa construcción.
} 
En tercer lugar, "el dato histórico del género, el hecho de que existe en la realidad social, de que tiene existencia concreta en formas culturales e incidencia actual en relaciones sociales, hace del género un problema político que no puede ser eludido ni apartado" (DE LAURETIS, 1994, p. 111). ${ }^{2}$

Como sostiene Laera, "la imagen de la violación permite pasar rápidamente del plano literal al metafórico a la vez que atravesar todos los niveles: violación de los espacios y de los cuerpos, violación como transgresión de las costumbres y de la lengua, y, sobre todo, la violación como ilustración privilegiada del conflicto entre clases" (LAERA, 2010, p. 163). Podemos, entonces, señalar que si las escenas de violación, su representación literaria y su tratamiento en la crítica facilitan esas lecturas metafóricas y habilitan una interpretación de las relaciones sociales, a la vez eliden la marca de género de la violencia de la sexual, la invisibilizan, componiendo de ese modo un archivo patriarcal. ${ }^{3}$

En contraste con estos usos y análisis metafóricos de la violencia de género, las escrituras de mujeres, de las cuales vamos a tomar algunos ejemplos, constituye una serie desobediente a ese archivo. ¿Cómo dialogan las narrativas con el contexto social argentino? ¿Qué situaciones hacen visibles y qué voces audibles? ¿Cómo narran la violencia contra las mujeres y desde qué estrategias formales intentan poner palabras al dolor? Mientras que el uso de la violencia como metáfora de la política elide la posición de quienes son víctimas de la violencia en la vida real, reforzando el borramiento de las mujeres como sujetos, las políticas de representación que lleva adelante el movimiento de mujeres insisten en otras formas de narrar, otras posiciones de enunciación. Esas intervenciones políticas habilitan a la vez nuevas condiciones sociales de escucha que desnaturalizan la violencia contra las mujeres y extienden sus efectos en las formas artísticas, prácticas culturales, representaciones en el campo literario.

Tal es el caso de los textos que analizamos en este ensayo. Beya, de Gabriela Cabezón Cámara e Iñaki Echeverría (2013), Chicas muertas, de Selva Almada (2014) y Por qué volvías cada verano, de Belén López Peiró (2018), son obras donde las narradoras construyen una memoria, se erigen en testimoniantes y postulan un espacio donde las mujeres toman la palabra y les dan la palabra a otras a través de procedimientos literarios marcados fuertemente por las emociones. En todos los casos, las violencias sexistas son presentadas poniendo de relieve perspectivas cercanas a las voces de las víctimas. Las leemos en contraposición al uso de la violencia como metáfora de la política; un uso que, como ya señalamos, elide la posición de quienes son víctimas de la violencia en la vida real, reforzando la borradura de las mujeres como sujetos. De esta manera, las escritoras tejen en su vida cotidiana $-y$ en sus narrativas- lazos feministas y genealogías de mujeres. Además, las tres obras presentan la particularidad de que abordan como tema principal tópicos clásicos del feminismo -la prostitución, el femicidio y la violación- desde puntos de vista cercanos a quienes padecen esas violencias.

Como antecedente de esta estrategia formal se puede mencionar la novela Enero, de Sara Gallardo, publicada por primera vez en Argentina en 1958, y reeditada en 2018. Enero tiene como protagonista a Nefer, una joven de dieciséis años, que vive y trabaja en una zona rural, quien una noche a la salida de una fiesta es violada por un trabajador del pueblo. La novela exhibe la subjetividad de esa adolescente, su deseo sexual, su rechazo por la maternidad impuesta y la posibilidad secreta de un aborto que es centro del relato, pero que nunca se nombra (LAERA, 2018). En este sentido, no es casual su reedición en el actual contexto argentino, en el que se están haciendo audibles las voces de víctimas de violencia de género.

La posibilidad de esta escucha hoy en Argentina tiene una larga historia, con momentos especialmente intensos y variados. En el momento de la transición democrática, fuertes demandas del movimiento de mujeres visibilizan la violencia sexual y generan acciones para denunciarla, como el "Tribunal de Violencia contra la Mujer", que varias organizaciones feministas impulsaron a fines de 1983 a raíz del caso Adriana Montoya (Silvia CHEJTER, 1990; Alejandra OBERTI, 2019), 0 los planteos presentes desde el primer Encuentro Nacional de Mujeres (1986) acerca de las formas específicas de violencia que sufrieron las mujeres en la dictadura. A partir de 2015, escritoras, periodistas, activistas y víctimas de la violencia de género produjeron una serie de acciones con profundo impacto social que transformaron la mirada social sobre la violencia hacia las mujeres. Desde ese momento tuvo lugar una oleada de manifestaciones y protestas del movimiento de mujeres, que en los últimos años se han aglutinado bajo la consigna "Ni una menos," con convocatorias multitudinarias tanto en la Ciudad de Buenos Aires como en otras ciudades del país, e incluyeron un "paro de mujeres," que afectaba las actividades productivas y de reproducción de la vida cotidiana, facilitando la participación y visibilizacioin del lugar subordinado de las

\footnotetext{
${ }^{2}$ También otras feministas se dedicaron a poner en evidencia aquellos textos del pensamiento occidental en los que la violencia y la opresión contra las mujeres funcionaba como metáfora de funcionamiento del orden social. Es el caso, por ejemplo, de Gayle Rubin (1986), quien ha cuestionado el modo en que Levi Strauss y Freud pensaron simbólicamente el intercambio de mujeres como el momento de entrada de los sujetos en la cultura, sin poder advertir las consecuencias negativas que esa estructuración presentaba para las mujeres.

${ }^{3}$ En un trabajo que retomaremos más adelante, Mónica Szurmuk y Alejandro Virué (2020) utilizan la expresión "archivo patriarcal" para referirse al modo en que la voz y la experiencia de las mujeres han sido invisibilizadas.
} 
mujeres en la sociedad, la discriminación que sufren en los mercados de trabajo y el no reconocimiento del trabajo doméstico (Verónica GAGO, 2018). Multitudinarias fueron también en 2018 las marchas en apoyo al proyecto de ley para la interrupción voluntaria del embarazo.

Estas manifestaciones retoman experiencias organizativas y expresivas elaboradas desde los movimientos de mujeres y los feminismos en el país que, tras la recuperación de la democracia en 1983, han visibilizado las violencias a las que son sometidas las mujeres -y otros cuerpos femeninos- por parte de los poderes estatales, así como de una sociedad cómplice en su desatención (Claudia $\mathrm{BACCl}, 2017)$. Es en este contexto político que las narradoras argentinas contemporáneas producen obras que tematizan la violencia contra las mujeres. Estas escrituras elaboran críticas al patriarcado, al sexismo y a la violación de los derechos humanos de las mujeres, trazando continuidades entre las violencias del pasado y las del presente para poner el foco en la responsabilidad estatal y social.

A continuación, indagaremos en las tres obras mencionadas. En primer lugar, analizaremos Beya, de Cabezón Cámara y Echeverría, focalizando en los sentidos afectivos que produce el dispositivo de enunciación de la voz en segunda persona. En segundo lugar, nos detendremos en Chicas muertas, de Almada, para intentar comprender el modo en que la recuperación de las historias de las jóvenes asesinadas posibilita la conformación de un archivo feminista u hospitalario. En tercer lugar, examinaremos Por qué volvías cada verano, de López Peiró, deteniéndonos en la conformación de una polifonía de voces que habilita tanto el desplazamiento subjetivo de la autora/narradora como una redistribución más justa de la vergüenza. Finalmente, y a modo de cierre, sugerimos que estas escrituras pueden ser leídas desde la figura de Sara Ahmed de la feminista aguafiestas (AHMED, 2019) porque se proponen intervenir políticamente poniendo en evidencia el funcionamiento del sexismo y la violencia en espacios que requieren que ese sexismo no sea mencionado para seguir funcionando felizmente.

\section{Beya: una voz que acompaña y protege}

Beya (le viste la cara a Dios) es una novela gráfica sobre la trata de personas que utiliza el comic y la crónica policial para contar la historia de una joven encerrada en un prostíbulo. Si bien el modelo de encierro, secuestros, torturas y ejecución que despliega la novela de Cabezón Cámara y Echeverría es muy próximo a los testimonios de la detención clandestina de la dictadura, la narración se emplaza en la lógica prostibularia y desde allí cuenta las violencias extremas a las que son sometidas las mujeres prostituidas. La protagonista de la historia sufre, enloquece, especula, intenta zafar, construye una realidad alternativa, planea fugas tan imposibles como desesperadas. Toda la red de complicidades es denunciada en el libro donde policías, gobernadores, cafishios y jueces son parte de la trama de violencia sexual del puticlub de Lanús, en el que está secuestrada Beya (ese no es su verdadero nombre, sino que es el apodo que allí le han dado, la historia nunca nos revela su nombre).

La primera versión de esta obra data de 2012 y fue hecha a pedido de una editorial española que quería publicar cuentos infantiles clásicos en versión para adultos. A Cabezón Cámara y Echeverría les tocó La bella durmiente. En una entrevista, Cabezón Cámara contó que al principio le parecía que no tenía mucho para decir de una chica atada en una cama, pasiva y presa de una maldición. Pero de repente se dio cuenta de que la situación que describía era la de una chica en situación de trata: "secuestrada, torturada, violada, desaparecida" (Sol AMAYA, 2013). ${ }^{4}$ Con esta obra, las autoras buscaron intervenir en la escena política y social conmovida por el secuestro y desaparición de Marita Verón y el accionar de las redes de trata que salió a la superficie con el juicio que se llevó a cabo en 2012. El procedimiento del juicio y su impúdica absolución fueron un caso inédito en la historia de la justicia argentina. ${ }^{5}$ La novela está estrechamente vinculada con esos hechos políticos inmediatos, que están aconteciendo y visibilizándose en el mismo momento en que se produce el texto (Nora DOMÍNGUEZ, 2013). La obra no sólo se nutre de esos hechos inmediatos, sino que también otras experiencias concentracionarias remiten a la situación de encierro y tortura de la protagonista. El nazismo y la dictadura argentina aparecen como experiencias similares de las que se valió la autora para trabajar el texto -pero también son experiencias que los/as lectores/as no podemos dejar de evocar al leer- que dan cuenta de la multireccionalidad de las memorias de diversos acontecimientos traumáticos (Michael ROTHBERG, 2009). Esa interferencia de las memorias de otras experiencias de violencia se hace

\footnotetext{
${ }^{4}$ Es interesante mencionar que la Bella durmiente es una historia inspirada en el cuento de hadas de tradición oral para adultos, Sol, Luna y Talía, publicado en 1634 por el italiano Giambattista Basile. La versión de Basile es una historia con contenidos de violencia, empezando por el hecho de que el despertar de la princesa no se produce por un beso sino por medio de una violación.

${ }^{5}$ En Argentina, en la provincia de Tucumán, tuvo lugar entre 8 de febrero de 2012 y diciembre del mismo año el primer juicio por un caso de trata ocurrido diez años antes. Había 13 imputados por el secuestro, la prostitución, el ocultamiento de datos y la usurpación de identidad de María de los Ángeles Verón. El fallo que absolvió a los imputados tuvo consecuencias inmediatas, en especial el pedido de juicio político a los tres jueces, uno de los cuales renuncioì al cargo horas más tarde.
} 
presente mediante referencias explícitas en la novela, por ejemplo, en el caso del epígrafe que retoma consignas de los organismos de derechos humanos respecto de las personas desaparecidas en dictadura. Beya abre con una reescritura de esa consigna, que muestra cómo las memorias con respecto a ciertos hechos violentos colaboran en la atención dada a otros, a la vez que inscribe a la violencia prostituyente en una serie de violencias socialmente conocidas, que convocan solidaridades y que movilizan a amplios sectores en la Argentina posdictatorial: "Aparición con vida de todas las mujeres y nenas desaparecidas en manos de las redes de prostitución. Y juicio y castigo a los culpables" (CABEZÓN CÁMARA; ECHEVERRÍA, 2013, p. 7). Lazos y nexos entre el terrorismo de Estado y el terrorismo sexual.

El gesto de Cabezón Cámara y Echeverría es similar al de las teóricas feministas que mencionábamos anteriormente. Si de Lauretis y Rubin cuestionaban los usos de la mujer como metáfora en el pensamiento occidental, para exhibir el modo en que esas matrices metafóricas operaban de modo sexista, Cabezón Cámara y Echeverría reescriben en clave de violencia de género la clásica obra literaria infantil en la que una mujer hermosa se encuentra inmovilizada hasta que es despertada con el beso romántico de un hombre. La reescritura feminista traduce esa narrativa en una matriz opresiva, violenta y sexista. Si La bella durmiente pretendía operar como una metáfora de la feminidad y del amor, Beya elimina toda metáfora para pasar en cambio al plano de la realidad de la violencia: ya no hay bella durmiente, sino una mujer esclavizada y prostituida en una red de trata.

La disposición del texto en versos -que muchas veces no terminan en un mismo recuadro, obligando a buscar la continuación para recuperar un sentido relativamente completo- acompaña los dibujos que muestran cuerpos fragmentados: una mano, una boca, un ojo, siempre en primeros planos deformes. La violencia tiene -en el texto y en las imágenes- una materialidad corporal muy concreta y alejada de cualquier mirada ingenua acerca de la prostitución. El cuerpo sometido brutalmente está siempre en escena transformado en un "puñado de carne en una bandeja de coto" (CABEZÓN CÁMARA; ECHEVERRÍA, 2013, p. 86) o en un "gato viejo enfermo" (CABEZÓN CÁMARA; ECHEVERRÍA, 2013, p. 63). Un cuerpo atravesado por "marcas de mil mordidas y con tajos de uñas duras y con la concha y el orto casi deshilachados" (CABEZÓN CÁMARA; ECHEVERRÍA, 2013, p. 60). La violencia no está en lugar de otra cosa, es pura corporalidad sin distanciamiento.

Con una enunciación que se desplaza por el corazón mismo del prostíbulo, el relato focaliza las vivencias de Beya y presenta el repertorio de suplicios como parte de la lógica de la compra de los cuerpos prostituidos como mercancía. La figura del rufián y la del cliente como torturadores, la violación como una forma de sexo para éstos y no meramente como agresión y la diferencia de género como un problema que no puede ser eludido completan una fórmula eficaz para dar cuenta de una retórica de la violencia que se nutre de prácticas sociales de violencia que ubican a varones y mujeres en una relación antagónica y asimétrica.

Beya es una narración en segunda persona (es una constante a lo largo de toda la novela) que sabe todo, anticipa los resultados de las acciones y resulta a la vez una guía en el infierno y una advertencia a quien lee. Es un recurso que transmite incomodidad, porque mientras leemos le estamos hablando a la protagonista desde uno de sus yo, y esa voz nos obliga a acompañarla a lo largo de todo su periplo. Ese dispositivo de la segunda persona supone una política de la voz autoral que fluctúa entre la orden y el "abrazo poético" protegiendo a su personaje (DOMíNGUEZ, $2013, s / p)$.

\author{
Y así empezaste a saber \\ Que en el centro de ese antro \\ Lo que sos iba a ser muerto \\ Como restos de un puchero \\ Arrojados a la calle \\ Y el nombre de cada cosa \\ Enfermo de podredumbre \\ Desde el suelo del bautismo \\ Que te hicieron padecer \\ Los rufianes del sabor, \\ El puticlub de Lanús \\ Donde conociste a Dios. \\ (CABEZÓN CÁMARA; ECHEVERRÍA, 2013, p. 27)
}

Como señala Nora Domínguez, "el dispositivo de la segunda persona recubre el desamparo de su personaje o le señala que las vías de la salvación por la marginalidad incluyen 'dar muerte'” (DOMÍNGUEZ, 2013, s/p), hacer de cuenta que ha sido definitivamente sometida, dejarse 
también acariciar por el rufián. La narración parece un ciclo espiralado de repeticiones del sufrimiento, un descenso al infierno que no tiene fin porque ni siquiera el delirio le es permitido.

El prostíbulo que crean Cabezón Cámara y Echeverría se parece mucho a los centros clandestinos de detención de la dictadura argentina. Ese conocimiento social se puede leer en diferentes aspectos del texto. Como ya señalamos, en el secuestro, el encierro y la tortura y en el epígrafe. Pero también en la creación de una nueva lengua que cita tanto los lugares comunes de las narrativas de la violencia popular, como el modelo que emerge de la represión estatal en la dictadura que también creó una suerte de "diccionario del chupadero." 6

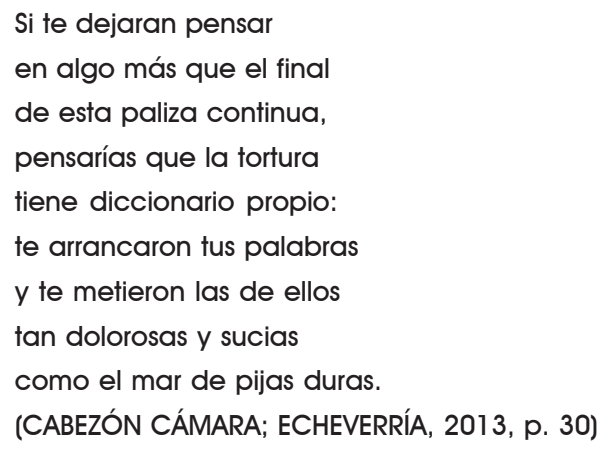

I delirio está atravesado por un llamado místico, Dios, la virgen, el crucificado. Así, la locura le sirve de refugio de la desesperación, pero también la lleva a inventar (o no) la historia de su salvación que implica fingir, mentir, entregarse, matar, mostrarse cómplice, seducir para finalmente lograr (con ayuda externa, pero tomando las armas por mano propia) salir del infierno del prostíbulo a tiro limpio. En su intención de poner palabras a la violencia sufrida, Beya puede leerse como una respuesta ética al dolor del otro (AHMED, 2015), que no intenta arrebatar ese dolor-en el sentido de reivindicarlo como propio- sino que trata de verse afectada por algo que no se puede conocer ni sentir. En este punto es fundamental la narración en segunda persona, porque esa voz forma parte de la estrategia de supervivencia del personaje.

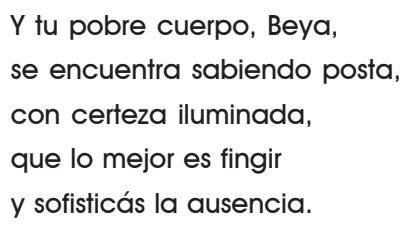

Ese arte de la ausencia es una estrategia al estilo de las "tretas del débil" (Josefina LUDMER, 1984). Por medio de la ausencia, especie de trance místico que la contiene respecto del exterior violento, Beya planea su fuga. En ese devenir pedirá pasar a la sección sadomasoquista para entrenarse y logrará que un teniente enamorado le entregue un arma: una metralleta Miniuzi con la que una noche, vestida de sadomasoquista, acribillará a todas las personas presentes en el prostíbulo y se escapará.

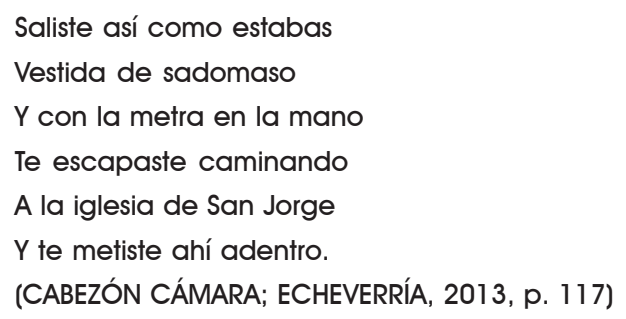

Unas páginas más adelante, la salida:

Y le sacaste la ropa

A una Virgen de Lujan

\footnotetext{
${ }^{6}$ La conexión entre el centro clandestino y el prostíbulo tiene lugar también en la novela de Félix Bruzzone, Campo de Mayo, en donde la madre desaparecida del protagonista "aparece" en un prostíbulo cercano al lugar en el que se la vio por última vez en dictadura.
} 


\author{
Así que quedaste linda \\ Con el vestido celeste \\ Que suele usar la patrona \\ $Y$ tu uniforme de sado. \\ (CABEZÓN CÁMARA; ECHEVERRÍA, 2013, p. 121)
}

La narración de Beya muestra que la violencia no está simplemente en el lenguaje o en la representación, sino que también es engendrada por ellos (DE LAURETIS, 1994). Tomar en cuenta, entonces, la experiencia concreta de la violencia sexual (como lo hacen Cabezón Cámara y Echeverría) es un modo de movilizar afectos y poner en el centro de la lectura el sufrimiento, las resistencias, la fuerza de la ira.

\title{
Chicas muertas: un archivo hospitalario
}

Los textos de Cabezón Cámara y Echeverría, Almada y López Peiró traen de manera particular y renovada algunos de los temas clásicos del feminismo: trata de mujeres, femicidio, violencia sexual y abuso. Pero ¿cómo traen estos temas? ¿De qué modos estas narrativas representan, recuperan y construyen la violencia contra las mujeres? ¿Cómo podemos leer en estas obras los movimientos ficcionales y no ficcionales de la violencia (DOMíNGUEZ, 2013b)? Se trata de obras que utilizan recursos variados: hacen presente el archivo, trabajan con la voz propia y del/la otro/ a, recurren a la gráfica. A través de sus escuchas y sus escrituras, intervienen sobre el archivo produciendo la posibilidad de un desplazamiento desde un archivo patriarcal hacia uno hospitalario, afectivo y feminista. Como señalan Mónica Szurmuk y Alejandro Virué:

(...) dentro del universo de la literatura existen objetos privilegiados para la construcción de un archivo hospitalario. Nos referimos a aquellos textos escritos por autores que, debido a su género, clase, etnia, religión u orientación sexual, ocupan un lugar marginal en los archivos oficiales. La literatura escrita por mujeres tiene un lugar privilegiado en ese archivo, un espacio donde se cobijó históricamente lo que no se podía decir (por censura o por normas de la época) y también lo que todavía no se podía pensar. (SZURMUK; VIRUÉ, en prensa, s/f)

Estos textos operan de ese modo y producen, así, una transformación en los lugares comúnmente asignados a las mujeres y nos obligan -como lectores/as- a escuchar y a leer de otra manera.

Entre la ficción, la autobiografía y la crónica con trabajo de archivo, Chicas muertas arranca con una anécdota personal. La narradora describe detalladamente la mañana del 16 de noviembre de 1986 en Villa Elisa, un pueblo del interior de Entre Ríos. El asado familiar, el sol de verano, la radio sonando de fondo y la cotidianeidad interrumpida por la noticia del asesinato de Andrea Danne, en su cama, en su casa, en un pueblo cercano al de la narradora.

Yo tenía trece años y esa mañana, la noticia de la chica muerta me llegó como una revelación. Mi casa, la casa de cualquier adolescente, no era el lugar más seguro del mundo. Adentro de tu casa podían matarte. El horror podía vivir bajo el mismo techo. (ALMADA, 2014, p. 17)

El recuerdo del impacto que le produjo en su adolescencia este y otros asesinatos, dan inicio a la crónica y a una investigación personal desordenada que avanza un poco sin método y a los tropezones, pero con preguntas certeras: ¿qué hay de común en cada una de las muertes? ¿Por qué quedaron impunes? ¿Qué alcances tuvieron y tienen los asesinatos de estas mujeres?

La autora rescata del olvido tres casos de asesinatos de mujeres que quedaron impunes, con los que se ha obsesionado a lo largo de su vida porque le recuerdan que ella misma podría haber sido una de esas víctimas, y que estar viva en la actualidad es solo una cuestión de suerte (ALMADA, 2014). Las jóvenes asesinadas fueron Andrea Danne (19 años, asesinada el 16 de noviembre de 1986), María Luisa Quevedo (15 años, asesinada el 8 de diciembre de 1983) y Sarita Mundín (20 años, desaparecida el 12 de marzo de 1988).

Para escribir su crónica, Almada hace un trabajo de investigación minucioso que retoma en el texto a través de diversos materiales de archivo. Entrevista a familiares y amigos de las víctimas, recolecta datos, revisa expedientes judiciales y la prensa, recoge evidencias. Pero acude también a su experiencia personal en relación con la violencia de género para darle textura y profundidad al problema de la violencia. Narra episodios vividos por ella y anécdotas del pueblo que le llegaron como rumores de boca de otras mujeres (María Celeste CABRAL, 2018). Junto a las historias de Andrea, María Luisa y Sara, se hilvanan historias de chicas violadas en caminos de tierra, chicas secuestradas por un grupo de amigos un sábado por la noche rumbo al baile del pueblo, niñas miradas con lascivia en una noche de Carnaval, mujeres a quienes todos sabían que sus maridos les pegaban, les administraban el sueldo, las mandaban a prostituirse $\circ$ les prohibían los labios pintados y los tacos altos. 
Pero todavía así no le alcanza. El texto alterna entre una narradora en primera persona identificada con la autora (que busca, investiga y relata diversas experiencias personales), una tercera persona que focaliza en la vida de las chicas muertas (a través de los materiales de archivo y las entrevistas) y una segunda persona traída al relato en diálogo con la narradora (la tarotista que invoca la voz de las chicas muertas). Tanto la voz de la vidente como la experiencia personal de Selva Almada vienen a hablar acerca de aquello de lo cual el archivo no tiene nada para decir. Porque, como señalan Szurmuk y Virué en su lectura de la obra de Tununa Mercado, "Lo que se llena con la experiencia personal no son los vacíos del archivo sino lo que nunca se archivó. Y la fuerza enorme que tiene [...] está en la exhibición de esta estrategia, en la revelación ante sus lectoras del procedimiento" (En prensa, $\mathrm{s} / \mathrm{f}$ ).

Un procedimiento que en el ensayo de Almada se puede ver en el esfuerzo de invocar la voz de las muertas a través del tarot y haciendo presente la experiencia de la narradora. Mostrando que hay propiedades en común entre ambas voces.

La manipulación de los datos de la historia verdadera según los recursos de la ficción literaria establece dentro de la crónica una contigüidad entre las chicas muertas y la experiencia de ser mujer en el mundo patriarcal y violento de la narradora. Por eso, alternativamente, el lugar de lo no archivado (lo in-archivable) es ocupado por el recurso a lo fantástico y a la experiencia propia.

En un texto a propósito de El desierto y su semilla, la novela donde Jorge Barón Biza recrea el crimen que cometió su padre, Nora Domínguez se pregunta:

¿Qué se tiende entre la vida, su memoria y la tardía reconstrucción literaria? Sin duda, una serie de conexiones, todas zigzagueantes e inestables, que cancelan cualquier brote de homogeneidad y reflejo. Sin embargo, también puede afirmarse que tanto la vida como la literatura son espacios donde, reales o disfrazados se dejan inscribir los datos precisos, los incidentes concretos, las historias singulares, los nombres propios. (DOMíNGUEZ, 201 1, p. 2)

En ese sentido es elocuente el modo en que Chicas muertas recupera las voces de la madre y de la tía de la narradora, construyendo una genealogía feminista. Varias de las anécdotas que narra en el libro le llegaron a Almada por boca de su madre, que aparece como una figura de transmisión intergeneracional de saberes sobre la violencia de género. Cuando era chica, su madre le contó varias veces la misma anécdota personal. Al poco tiempo de casados el padre le amagó una cachetada y la madre le clavó un tenedor en el brazo. El padre nunca más se hizo el guapo. Escribe Almada:

No recuerdo ninguna charla puntual sobre la violencia de género ni que mi madre me haya advertido alguna vez específicamente sobre el tema. Pero el tema siempre estaba presente. Cuando hablábamos de Marta, la vecina golpeada por su marido (...) Cuando hablábamos de Bety, la señora de la despensa que se colgó en el galponcito de su casa (...) Mi madre hablaba de estas historias en voz alta y con indignación. (ALMADA, 2014, p. 53-56)

Asimismo, al final del libro la narradora vuelve sobre algo que le contó una tía joven y muy cercana cuando ella era una adolescente y juntas caminaban a la hora de la siesta por un camino de tierra. Es una historia que Almada ya había oído fragmentada algunas veces al pasar. Un primo cuarentón casi viola a la tía, que logró resistirse. "Nunca tuve tanto miedo y nunca tuve tanto valor como esa vez" (ALMADA, 2014, p. 183), le dijo su tía. Almada elige cerrar su libro con esa "pequeña victoria" que hace que hoy la tía esté viva. La sensación de peligro, el miedo, pero también los lazos afectivos que unen las generaciones cierran el círculo y establecen puentes entre lo narrado y lo vivido.

Los modos en que nos acercamos a ciertas dimensiones subjetivas y los lugares otorgados a los afectos intervienen en estos relatos para armar otro archivo. Es "un archivo hospitalario", para usar el término que Szurmuk y Virué (en prensa) elaboraron inspirados en la idea de mal de archivo de Jacques Derrida. Un archivo hospitalario podría ser también un archivo afectivo o un archivo feminista. Es, en todo caso, un archivo que da cuenta de los daños corporales sufridos y un archivo que da hospitalidad al relato, lo acoge, le da un lugar.

El archivo hospitalario que construye Almada requiere de movimientos ficcionales y no ficcionales. A través de la ficción, de la investigación y de la experiencia propia repone voces no escuchadas y elabora un relato sobre la violencia contra las mujeres. Recupera las voces de las chicas muertas, pero también las de la tía y la madre. Son las voces de las víctimas y de las sobrevivientes. Voces de mujeres que permanecían en los márgenes del archivo pasan a ocupar el centro del relato.

\section{Por qué volvías cada verano: polifonía y redistribución de la vergüenza}

Por qué volvías cada verano es la historia del abuso sexual padecido por la autora durante varios años en su adolescencia por parte de su tío, el comisario de Santa Lucía, un pueblo de la 
Provincia de Buenos Aires. En el libro, Belén López Peiró denuncia, cuenta, se reconoce como víctima de su tío con el cual la unía una relación de afecto y se apropia de las herramientas para gritar, gritarle a su familia y los/as lectores/as el abuso del que fue víctima. Nos convoca a comprometernos con lo que nos cuenta, con lo que le pasó, pero también a que reconozcamos las herramientas para situarse en otro lado, para salir del lugar de víctima.

El libro muestra justamente ese movimiento que tiene como punto de partida el asumirse como víctima y denunciar la violencia sufrida pero que se desplaza a través de la escritura hacia una zona diferente. Un movimiento -de escritura testimonial y de denuncia penal- que le permite desprenderse de eso adherido a su cuerpo (LÓPEZ PEIRÓ, 2018) por la experiencia del abuso y pasárselo al victimario.

El texto es polifónico, coral: habla la víctima, su abogado, la Justicia, el fiscal, los miembros de la familia, la madre, el hermano, el padre, el novio de la madre, la tía, la prima, los otros parientes del pueblo, el novio, la psicóloga, la pediatra, los peritos y el tío abusador. Un coro que viene a decir las reacciones ante el abuso, diciendo, callando, modalizando, justificando, limitando, creyendo, no creyendo, apoyando, esquivando. En esa polifonía se deja ver la trama de complicidades y silencios que hizo posible la violencia y su persistencia en el tiempo. Porque no se trató solo del tío y sus actos de abuso, sino también de quienes no vieron, no escucharon, no quisieron o no pudieron ver ni escuchar. También de quienes, tras saber, decidieron no creer en los hechos relatados por la autora para, en cambio, defender al tío abusador.

La exhibición de esa trama social de complicidades posibilita la no reducción de la violencia contra las mujeres a un esquema binario donde solo hay dominantes y dominadas, verdugos y víctimas (Tamar PITCH, 2014). Para mostrar en cambio que se trata de un entramado social más amplio, tan bien descripto por Rubin (1986), en el cual las mujeres son el objeto que circula y se intercambia como regalo entre varones o familias en función de la reproducción del orden patriarcal. Tanto la pregunta del título ("por qué volvías cada verano") como la frase con la que su abuela postrada la despedía son punzantes: "Cuidate, querida, que el peligro está donde menos lo esperás" (LÓPEZ PEIRÓ, 2018, p. 102). ¿Qué significan esas preguntas? ¿Qué implica el mandato de cuidarse pronunciado para (o contra) una adolescente? ¿Tal vez que solo ella puede cuidarse? ¿Que las/os adultas/os que están cerca solo pueden entregar a la joven como cordero al sacrificio?

Merece una lectura aparte el trabajo con el archivo que hace hablar al texto duro y frío que es el expediente judicial, las pericias, las declaraciones de los testigos y que nos regala incluso el resultado de la pericia que le hacen al abusador: "limitada capacidad de introspección de sus acciones" (LÓPEZ PEIRÓ, 2018, p. 122), dice. O las preguntas de alguien (por ejemplo, el secretario del Juzgado de San Pedro en el cual está radicada la causa) que, aclara que son las últimas, le realiza tras resaltar que en realidad no la quiere hacer hablar, que son solo detalles que sumarían a la causa. Preguntas que en el libro aparecen ubicadas solas y se van alternando con otras páginas en las que continúan hablando las otras voces. La visualización de cada una de estas preguntas en una página en blanco evidencia la fuerza y el efecto que ese detalle posee sobre la narradora: "¿Crees que tu tío abusó también de su hija?” (LÓPEZ PEIRÓ, 2018, p. 105). “¿En algún momento fue violento con vos? Digo, sí, más allá de estos hechos” (LÓPEZ PEIRÓ, 2018, p. 107). "¿Cómo explicás la ausencia de tus padres?" (LÓPEZ PEIRÓ, 2018, p. 109). “¿Podrías ser un poco más precisa?" (LÓPEZ PEIRÓ, 2018, p. 111). “¿Por qué crees que te molesta que te mire la espalda?" (LÓPEZ PEIRÓ, 2018, p. 113). “¿Qué consecuencias te trajo todo esto?” (LÓPEZ PEIRÓ, 2018, p. 115). Espanta la última pregunta que le hacen, que es a la vez la clausura del libro: "Y, decime, ¿qué se siente ser abusada?" (LÓPEZ PEIRÓ, 2018, p. 124).

Pero lo que más se destaca es el trabajo sobre la propia voz que está en el texto desde el comienzo y crece a lo largo de las páginas. El libro, además de ser una denuncia del entramado homosocial violento, es la forma a través de cual la mujer que padeció violencia puso en palabras su experiencia y la hizo pública. En ese sentido, el libro puede ser leído como un testimonio que es a la vez "la voz de lo singular y de lo social" (Susana KAUFMAN, 2014, p. 102) y que al encontrar una escucha que legitima los sucesos acontecidos tiene un efecto reparador, que habilita al sujeto en la elaboración del trauma. La escritura así parece tener cierta fuerza reparatoria. Algo de eso se deja entender en la contratapa del libro escrita por Gabriela Cabezón Cámara, en cuyo taller se gestó la novela de López Peiró. Para Cabezón Cámara, el hecho principal del libro, su ser un acontecimiento, tiene que más que ver con la posibilidad de ser escrito y publicado, que con lo que se dice allí. Escribe Cabezón Cámara: "Acá está la mujer que fue la nena que ese tipo quiso romper para su uso personal. Y está toda entera, fuerte, hablando de lo que da tanta vergüenza hablar. Escribiendo contra todos los que intentaron callarla. Contra sí misma, incluso, a veces" (CABEZÓN CÁMARA; ECHEVERRÍA in LÓPEZ PEIRÓ, 2018, contratapa).

Por medio de la denuncia, la escritura y la publicación del libro, López Peiró se comporta como, lo que podríamos llamar junto con Sara Ahmed, una "feminista aguafiestas" (AHMED, 2019). En los términos de esta autora, una feminista es una aguafiestas porque arruina la felicidad o el 
regocijo de los otros, al mostrar el sexismo o la violencia existente en un objeto o discurso que para esos otros era pensado como causa de felicidad. La puesta en duda de ciertos discursos establecidos como verdades inalterables hacen que las feministas sean leídas por los otros como aguafiestas, otros que pueden llegar a designarlas, entonces, como las causantes de la infelicidad (AHMED, 2019). Cuando la narradora del libro de Peiró saca a la luz el abuso, todos se preocupan por el daño que el escándalo y la denuncia pueden causar a la familia y a la comunidad (o sea por la actitud de la víctima) y no por el abuso (es decir, por la actitud del perpetrador). "A vos no te importa, pero ahora en navidad vamos a ser solo nosotros cuatro" (LÓPEZ PEIRÓ, 2018, p. 29), la interpela su madre, echándole en cara todo el sufrimiento padecido desde que su hija habló. La hija pasa a ser el problema. Así, describe Ahmed el funcionamiento de estas dinámicas familiares.

Diga lo que diga, la que habla como feminista es, por costumbre, la causa de la discusión para los demás. Es ella quien frena la fluidez de la comunicación. La cosa se tensa. Ella tensa las cosas. Podemos empezar a presenciar qué encierra esta dinámica. El problema no se limita al contenido de lo que está diciendo. No solo está diciendo cosas que están mal: también está entrometiéndose en algo, el logro de la representación de la familia, o de un nosotros u otro, que es creado por esto que no se dice. (AHMED, 2018, p. 61)

Esa posición de aguafiestas le permite a la autora/narradora primero poder reconocerse como víctima para luego salirse de ese lugar hacia otro, en el que, como afirma hablándose a sí misma: "No seas el desecho que pensó ese hijo de puta" (LÓPEZ PEIRÓ, 2018, p. 118). Y en ese proceso, lo que se desliza de un sujeto a otro es la vergüenza. Si al comienzo era un afecto adherido al cuerpo de la adolescente - a quien la familia del tío humilló tirándole a la basura unas "bombachas vencidas por las hormonas" (LÓPEZ PEIRÓ, 2018, p. 7)- hacia el final, la vergüenza será del abusador, de la sociedad y de todos/as quienes sostuvieron, por acción u omisión, esa violencia sin poner reparos.

En su estudio sobre las posibilidades de reparación a mujeres víctimas de crímenes sexuales y de género durante el conflicto armado en Perú, Kimberly Theidon sostiene que existe en el dar y recibir testimonio de las mujeres un "deseo de justicia distributiva", en la que es necesario incluir la vergüenza. "Algo que puede ser redistribuido es la vergüenza que fue depositada exclusiva e injustificadamente en las mujeres: esta vergüenza deberían sentirla los violadores, que hasta la fecha gozan de una impunidad absoluta" (THEIDON, 2011, p.75). Cuando terminamos de leer el libro de López Peiró, sentimos que algo de esa justicia redistributiva ha comenzado a operar, que la atribución de vergüenza y culpa retorna sobre quienes la generaron y que esa mujer joven ha sobrevivido para dar testimonio no solo se su ser "víctima" sino de su salirse hacia otros posicionamientos posibles. De esta manera, sortea "la fetichización de la herida" (AHMED, 2015, p. 66) para, en cambio, proponer formas alternativas y productivas de agencia subjetiva y política.

\section{Escrituras aguafiestas}

En los textos analizados encontramos una contigüidad entre las experiencias de las narradoras y la de ser mujer en el mundo patriarcal y violento. Son trabajos que hacen visibles y comprensibles los alcances de la violencia, los modos en que ésta incide en la vida de las mujeres y las variadas formas de resistencia y de producción de modos de vida alternativos. En ese sentido, mientras el uso de la violación como metáfora de la política elide la posición de quienes son víctimas de la violencia en la vida real -y nos hace pensar en el corpus literario argentino como un archivo patriarcal, que borra a las mujeres justamente porque aparecen recurrentemente como metáfora, metonimia o cifra de relaciones de poder que fundan la nación, la patria, la clase, el contrato entre varones- estas obras contemporáneas, escritas por mujeres, utilizando recursos variados, componen una nueva serie. Retomando las palabras de Nora Domínguez (2011), podemos decir que se trata de una serie zigzagueante e inestable donde las mujeres toman la palabra y les dan la palabra a otras, no en el sentido de darle la palabra al subalterno erigiéndose en superior, sino a través de la propia experiencia, en una horizontalidad verdadera y no artificiosa.

Las obras literarias que analizamos producen una torsión, una transformación en los lugares comúnmente asignados a las mujeres que nos obliga a escuchar y a leer de otro modo, ubicando la responsabilidad del otro lado de la situación enunciativa. La potencia del relato de unas sobrevivientes requiere, para completarse, de una escucha y una comprensión más integral y compleja de la experiencia que atravesaron. Relato que posibilita cierta justicia redistributiva.

Por otra parte, la serie que presentamos interviene a través de dimensiones subjetivas y afectivas produciendo, lo que, junto con Szurmuk y Virué, pensamos como un "archivo hospitalario" o un archivo feminista. Es, en todo caso, un archivo que da cuenta de los daños corporales sufridos y que da hospitalidad al relato, lo acoge, le da un lugar. Herramientas feministas, herramientas de escritura: "no te calientes, que su hombría se derrumba cada vez que sentás el culo y escribís. Deshacelo con palabras, acabalo en un punto y garchátelo entre comas," escribía López Peiró (2018, p.117). 
Esas torsiones en los lugares sociales, en las posibilidades de toma de la palabra y en los archivos habilitan movimientos en dos direcciones. Por un lado, permiten exhibir la trama social que organiza las violencias, exhibiendo los múltiples actores implicados y sus responsabilidades. Por otro, despliegan políticas de resistencia subjetivas y colectivas a las violencias y a los mandatos patriarcales que se extienden en múltiples campos.

Los temas de estos textos forman parte de la agenda de la literatura argentina contemporánea. Estas obras realizan así la labor de toda aguafiestas feminista: poner en evidencia el sexismo y la violencia que permanecían ocultas y/o eran asociados con cierta felicidad, postulando posiciones enunciativas novedosas que permitan imaginar otros futuros posibles. El movimiento feminista nos ha dado a las mujeres herramientas para contestar colectivamente a las violencias de las que somos víctimas y también nos ha impulsado a pensarnos más allá de las victimizaciones en un colectivo amoroso. Eso es el feminismo. Y eso implica, en general, ser una aguafiestas.

\section{Referencias}

AHMED, Sara. La política cultural de las emociones. México: PUEG-UNAM, 2015.

AHMED, Sara. Vivir una vida feminista. Barcelona: Bellaterra, 2018.

AHMED, Sara. La promesa de la felicidad: Una crítica cultural al imperativo de la alegría. Buenos Aires: Caja Negra, 2019.

ALMADA, Selva. Chicas muertas. Buenos Aires: Ramdom House, 2014.

AMAYA, Sol. "Lectura recomendada: Beya, Le viste la cara a Dios". Crónicas del crimen: historias que se escriben con sangre [online]. Buenos Aires, 2013. Disponible en http://blogs. lanacion.com.ar/ cronicas-del-crimen/libros/lectura-recomendada-beya-le-viste-la-cara-a-dios/. Acceso el 09/12/ 19.

$\mathrm{BACCl}$, Claudia. "Autonomía, experiencia y género: la protesta social contra la violencia sexual y de género en la argentina contemporánea". In: SEMINAiRIO INTERNACIONAL FAZENDO GENERO 11 \& 13TH WOMEN'S WORLDS CONGRESS, 2017, Florianópolis, UFSC. Anais Eletronicos, Florianópolis: UFSC, 2017. p. 1-13.

CABEZÓN CÁMARA, Gabriela; ECHEVERRÍA, Iñaki. Beya: (Le viste la cara a Dios). Buenos Aires: Eterna Cadencia, 2013.

CABRAL, María Celeste. "Chicas muertas de Selva Almada. Nuevas formas de la memoria sobre el femicidio en la narrativa argentina". Orbis Tertius [online]. Buenos Aires, 2018, v. 23, n. 48. ISSN 18517811. Disponible en https://doi.org/10.24215/1851781 1e094. Acceso el 10/12/19.

CHEJTER, Silvia. La voz tutelada. Violación y voyeurismo. Montevideo: Nordan, 1990.

DE LAURETIS, Teresa. "La violencia de la retórica. Consideraciones sobre representación y género". Travesías: Temas del debate feminista contemporáneo, Buenos Aires, n. 2, p. 103-125, octubre. 1994.

DOMÍNGUEZ, Nora. "Hechos, derechos, teorías". Cuadernos del INADI, Buenos Aires, n. 4, abril. 2011. Disponible en http://www.dirdocumentacion.net.ar/repo/modulos/buscador/documentos/cuadernosdel-inadi-04.pdf. Acceso el 10/12/19.

DOMÍNGUEZ, Nora. "Capturas". Escritores del mundo [online]. Mayo, 2013. Disponible en http:// www.escritoresdelmundo.com/2013/06/capturas-por-nora-dominguez.html. Acceso el 10/12/19.

DOMÍNGUEZ, Nora. "Movimientos ficcionales y no ficcionales de la violencia. Crímenes de mujeres". Aletria, Belo Horizonte, v. 23, n. 1, p. 137-147, jan-abr. 2013 b.

GAGO, Verónica. "\#NosotrasParamos: Notas hacia una teoría política de la huelga feminista". In: AAV. 8M. Constelación feminista. Buenos Aires: Tinta Limón, 2018. p. 7-23.

GALLARDO, Sara. Enero. Buenos Aires: Fiordo, 2018.

IGLESIA, Cristina. "Mártires o libres: un dilema estético. Las víctimas de la cultura en El Matadero de Echeverría y sus reescrituras". In: Letras y divisas: ensayo sobre literatura y rosismo. Buenos Aires: Santiago Arcos, 2004. p. 23- 31. 
KAUFMAN, Susana. "Violencia y testimonio. Notas sobre subjetividad y los relatos posibles". Clepsidra, Buenos Aires, n. 1, p. 100-113, marzo 2014.

LAERA, Alejandra. "Para una historia de la literatura argentina: orígenes, repeticiones, revanchas". Prismas, Buenos Aires, v. 14, n. 2, p. 163-167, diciembre. 2010. Disponible en http://www.scielo.org.ar/ pdf/prismas/v14n2/v14n2a05.pdf. Acceso el 10/12/19.

LAERA, Alejandra. "Sin Dios ni ley: Nefer, la personaje de Sara Gallardo". Revista Transas: Letras y artes de América Latina [online], Buenos Aires, 2018. Disponible en http://www.revistatransas.com/ 2018/08/07/sin-dios-ni-ley-nefer-la-personaje-de-sara-gallardo/. Acceso el 10/12/19.

LÓPEZ PEIRÓ, Belén. Por qué volvías cada verano. Buenos Aires: Madreselva, 2018.

LUDMER, Josefina. "Tretas del débil". In: GONZÁLEZ, Patricia; ORTEGA, Eliana (eds.). La sarteìn por el mango. Encuentro de escritoras latinoamericanas. Río Piedras: Ediciones Huracán, 1984. p. 4754.

OBERTI, Alejandra. "El feminismo como herramienta: afectos en el combate contras las violencias patriarcales". In: XIV JORNADAS NACIONALES DE HISTORIA DE LAS MUJERES Y IX CONGRESO IBEROAMERICANO DE ESTUDIOS DE GÉNERO, 2019, Mar del Plata, Universidad de Mar del Plata.

PITCH, Tamar. "La violencia contra las mujeres y sus usos políticos". Anales de la Cátedra Francisco Suárez, n. 48, p. 19-29, 2014.

ROTHBERG, Michael. Multidirectional Memory: Remembering the Holocaust in the Age of Decolonization. Stanford: Stanford University Press, 2009.

RUBIN, Gayle. "El tráfico de mujeres: notas sobre la economía política del sexo". Nueva antropología, México, v. VIII, n. 30, noviembre. 1986.

SZURMUK, Mónica; VIRUÉ, Alejandro. "La literatura de mujeres como archivo hospitalario: Una propuesta". El taco en la brea, Santa Fe, n. 10, en prensa.

THEIDON, Kimberly. "Género en transición: sentido común, mujeres y guerra". Cadernos Pagu, Campinas, n. 37, p. 43-78, jul-dic. 2011.

VIÑAS, Davis. Literatura argentina y realidad política. De Sarmiento a Cortázar. Buenos Aires: Jorge Álvarez, 1971.

Mariela Peller (mariela_peller@hotmail.com) es socióloga y doctora en Ciencias Sociales (UBA). Docente de teoría feminista y estudios de género en la carrera de Sociología (FSoc-UBA). Investigadora del CONICET en el Instituto Interdisciplinario de Estudios de Género (FFyL-UBA). Participa como integrante y directora en Proyectos de Investigación (UBACyT y PICT). Ha publicado artículos sobre memoria, historia reciente, teoría cultural y estudios de género.

Alejandra Oberti (alejandraoberti@gmail.com) es socióloga y doctora en Ciencias Sociales (UBA). Profesora regular de teoría feminista y estudios de género en las carreras de Sociología de la Universidad de Buenos Aires y la Universidad Nacional de La Plata. Investigadora del Instituto de Estudios de América Latina y el Caribe (FSOC-UBA) e integrante del Instituto Interdisciplinario de Estudios de Género (FFyL-UBA). Dirige Proyectos de Investigación (UBACyT y PICT). Ha publicado artículos y libros sobre memoria, historia reciente, teoría cultural y estudios de género. Dirige desde 2005 el Archivo Oral de Memoria Abierta.

\section{COMO CITAR ESTE ARTÍCULO, DE ACUERDO CON LAS NORMAS DE LA REVISTA:}

PELLER, Mariela; OBERTI, Alejandra. "Escribir la violencia hacia las mujeres. Feminismo, afectos y hospitalidad". Revista Estudios Feministas, Florianópolis, v. 28, n. 2, e72442, 2020.

CONTRIBUCIÓN DE AUTORÍA

Mariela Peller: concepción, elaboración y análisis del corpus, elaboración del manuscrito, redacción y discusión de conclusiones.

Alejandra Oberti: concepción, elaboración y análisis del corpus, elaboración del manuscrito, redacción y discusión de conclusiones. 


\section{FINANCIACIÓN}

Proyecto UBACYT "Pasado/presente. Afectos, testimonios y archivos en la cultura argentina contemporánea", Instituto Interdisciplinario de Estudios de Género, Facultad de Filosofía y Letras, UBA (2018-2020). Directora: Dra. Alejandra Oberti. Cátedra: "Identidades, discursos sociales y tecnologías de género", Carrera de Sociología. Facultad de Ciencias Sociales. UBA. Titular: Alejandra Oberti - CONICET.

\section{CONSENTIMIENTO DE USO DE IMAGEN}

No se aplica.

APROBACIÓN DE COMITÉ DE ÉTICA EN INVESTIGACIÓN

No se aplica.

\section{CONFLICTO DE INTERESES}

No se aplica.

\section{LICENCIA DE USO}

Este artículo está licenciado bajo la Licencia Creative Commons CC-BY Internacional. Con esta licencia se puede compartir, adaptar, crear material para cualquier objetivo, siempre que se le atribuya la autoría.

\section{HISTORIAL}

Recibido el 25/03/2020

Aprobado el 29/04/2020

Aprobado el 27/03/2019 